\title{
The Portuguese natural gas market in the European context
}

\author{
ABSTRACT \\ The Portuguese natural gas market is recent and small - being an emergent market according to 98/30/EC \\ directive. It is still protected and monopolistic while most of the other European countries have already \\ liberalised, at least partially, their natural gas markets. Along this paper, it is focused the issue of energy \\ market restructuring process in the European Union, and the present situation of this market in Portugal, \\ emphasizing the regional dimension of the Portuguese market. The natural gas price strategies followed \\ by Portuguese companies are analysed, and a comparison with the liberalised Europe is also attempted. \\ Special attention is given to the United Kingdom, as an example of a completely liberalised market and \\ also to Spain due to its close links to the Portuguese energy sector. Following the results obtained, \\ possible future scenarios for Portugal in a liberalisation context are presented.
}

KEY WORDS: Liberalisation, price policy, natural gas

\section{INTRODUCTION}

\subsection{AN OVERVIEW}

In the European Union (EU) important steps have been taken to achieve the liberalisation of the energy sector. First, the directive 96/92/EC was passed opening way to the liberalisation of the electricity sector; next the directive 98/30/CE, required also the opening of the gas markets. A derogation of the gas directive application was conceded to recent natural gas markets (considered emergent) allowing them to be protected during 10 years. Portugal is one of these exceptions.

The natural gas consumption in Portugal was initiated by the end of 1997, with the first supply to the newly built Tapada do Outeiro combined cycle gas turbine. Since then, power generation has been the major natural gas consumer.

The Portuguese natural gas market immaturity justifies its present market structure, characterised by a national monopoly for imports, storage and transportation and regional monopolies for distribution and supply. However the liberalisation of this market is expected to happen in the near future, as it is the case of the other EU member countries.

The focus of this paper is to analyse the present monopolistic structure of the Portuguese natural gas market. Being the energy prices a critical variable, the price strategies followed by the natural gas companies in Portugal will be examined, comparing the results within the EU. The regional dimension of 
this market is also addressed, attempting a comparative analysis among regions with access to natural gas and between regions with and without access to natural gas. The aim is to analyse if and how these regional differences are reflected on the regional energy consumptions structure evolution, since the introduction of the natural gas and, consequently, on the existence of industrial production costs differentials.

The paper begins by describing briefly the EU natural gas market and the state of implementation of the gas directive by the member states. In the second section, the Portuguese natural gas market is outlined. Here, the main players in this market are presented, along with a urban and industrial characterization of each region with access to the natural gas. In the third section, a comparative analysis of the energy prices in Portugal is presented, including the domestic and the industrial consumers. The question of how the energy consumption structure has changed in Portugal and across regions since the introduction of natural gas is also referred, along with a regional analysis of the energy prices. The Portuguese natural gas market is then compared with the equivalent EU market and, especially, with the United Kingdom, as an example of a completely liberalised market and with Spain due to its close links to the Portuguese energy sector. The main conclusions are summarised at the end.

\subsection{THE NATURAL GAS MARKET IN THE EU}

Natural gas is, nowadays, the primary energy source with the highest growing potential worldwide. The Energy Information Administration (2002) forecasts indicate that its use will double between 1999 and 2020, due to factors like price, environmental concerns, fuel diversification or market deregulation. The $\mathrm{EU}$ is no exception, with the projections indicating that the natural gas is the fastest growing fuel source, reflecting its increasing use for power generation.

In 1995, the EU published a White Paper (European Commission, 1995) where the most relevant goals of the European energy policy were outlined: overall competitiveness, security of energy supply and environmental protection. In this paper the liberalisation of the internal market for electricity and natural gas was pointed out as a primary and central aim. Since then, important steps have been taken to meet liberalisation objectives in the energy market. The electricity directive 96/92/EC and the gas directive 98/30/CE were adopted, laying down the rules to allow for real competition and to give the consumers a free choice of energy suppliers.

The competition in the EU countries has been gradually introduced, with countries adopting the system best suited to their particular circumstances, as it is foreseen in the directives. In October 2002, the Commission of the European Communities (2002) reported that the natural gas market was around $80 \%$ open to competition in the EU and would rise to $90 \%$ by 2008 . Only France and Luxemburg (excluding Portugal, Greece and Finland, which have derogations in place) do not envisage full market opening. 


\subsection{The Portuguese natural gas market}

The natural gas market in Portugal is recent and small. The recent introduction of this fuel in Portugal, was motivated by the three strategic key factors already pointed out for the EU (Direç̧ão Geral de Energia, 2002): Supply security, competitiveness and environmental concerns.

By the end of 1997, the natural gas consumption in Portugal was initiated. As shown in Figure 1, in 2001 it already represented $9.8 \%$ of total primary energy, overcoming all the government forecasts. This share is expected to grow to $21 \%$ in 2015 . At the same time the dependence of oil will reduce from $62 \%$ in 2001 to a predicted 53\% in 2015.

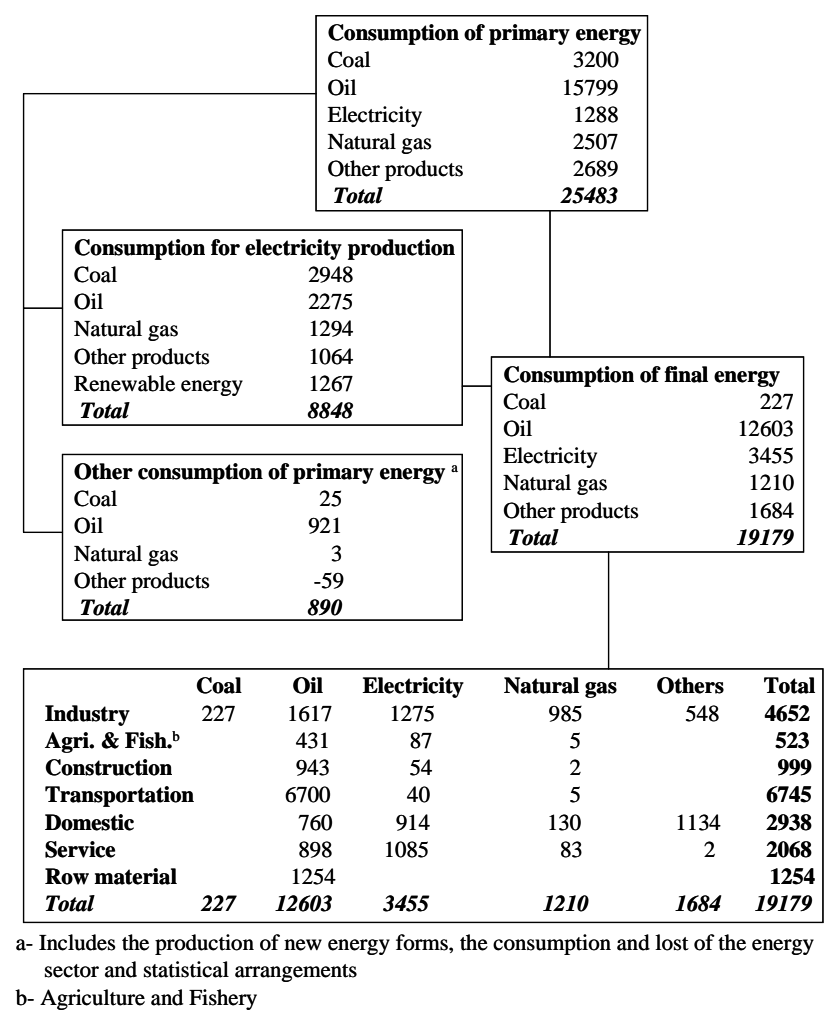

Figure 1- Energy balance 2000 (10 $0^{3}$ tones of oil equivalent- toe) (Source: DGE- Direcção Geral de Energia)

According to Table 1 electricity generation has been the largest natural gas consumer since the start up of the project, and as it is evident this sector still plays the most important role in the project viability. The amount of natural gas consumed by smaller domestic and industrial consumers (supplied by the distribution companies) is increasing, but still on a significant lower level than large industry and power production. 
Table 1- Volume of natural gas sold by consumption sector $\left(10^{6} \mathrm{~m}^{3}\right)$

\begin{tabular}{lccc}
\hline & Small consumers & Large industry & Power production \\
\hline 1997 & 22.2 & 46.6 & 26.6 \\
1998 & 121.8 & 242.4 & 402.4 \\
1999 & 219 & 492 & 1427 \\
2000 & 334 & 735 & 1174 \\
2001 & 436 & 950 & 1097 \\
\hline
\end{tabular}

Source: Galp Energia, 2001

The geographical location of Portugal (bordering only to Spain and to the Atlantic Ocean) implies that the energy imports are transported through Spain. Presently Portugal has only two international pipelines connections both in Spain. The third will be the liquefied natural gas terminal in Sines that it is expected to be completed in December 2003.

\subsubsection{The Portuguese market: industry structure}

The natural gas industry is composed by the following main elements: production, transportation, wholesale market, supply and distribution. Figure 2, shows the natural gas value chain in Portugal, presenting also the companies operating.

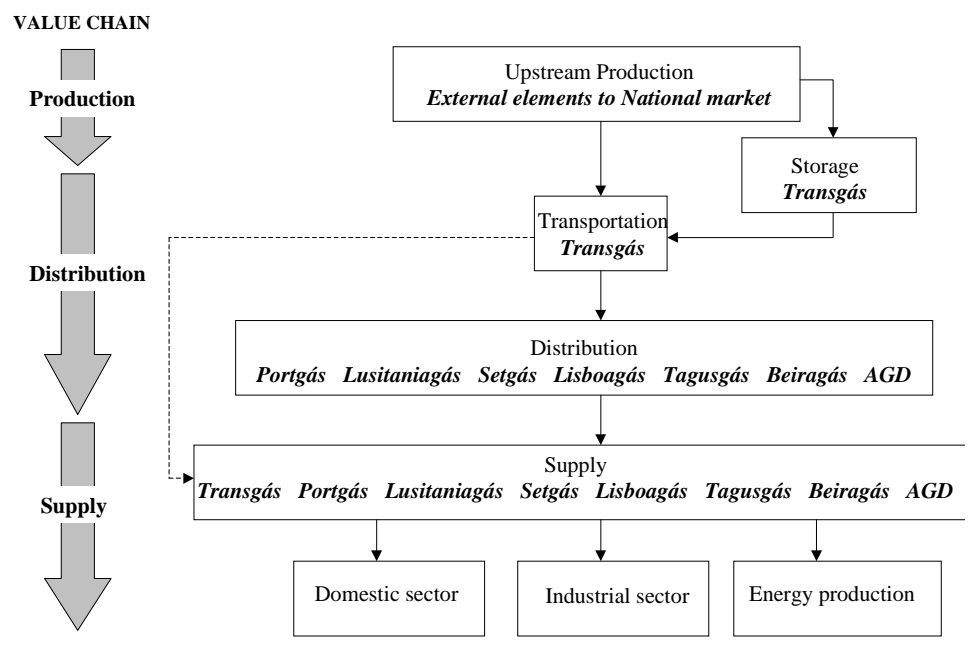

Figure 2- Natural gas value chain in Portugal (Based on : Oxera, 2000)

Transgás has the exclusivity of imports (presently form Algeria in the gaseous form and from Nigeria in liquefied form), high-pressure transport and of supply both the distribution companies and major national consumers. Each one of the distribution companies, operates in a regional monopoly distributing the lowpressure gas and supplying all the market sectors. 
Figure 3 presents the geographical area of operation of each one of these companies, along with some key indicators.

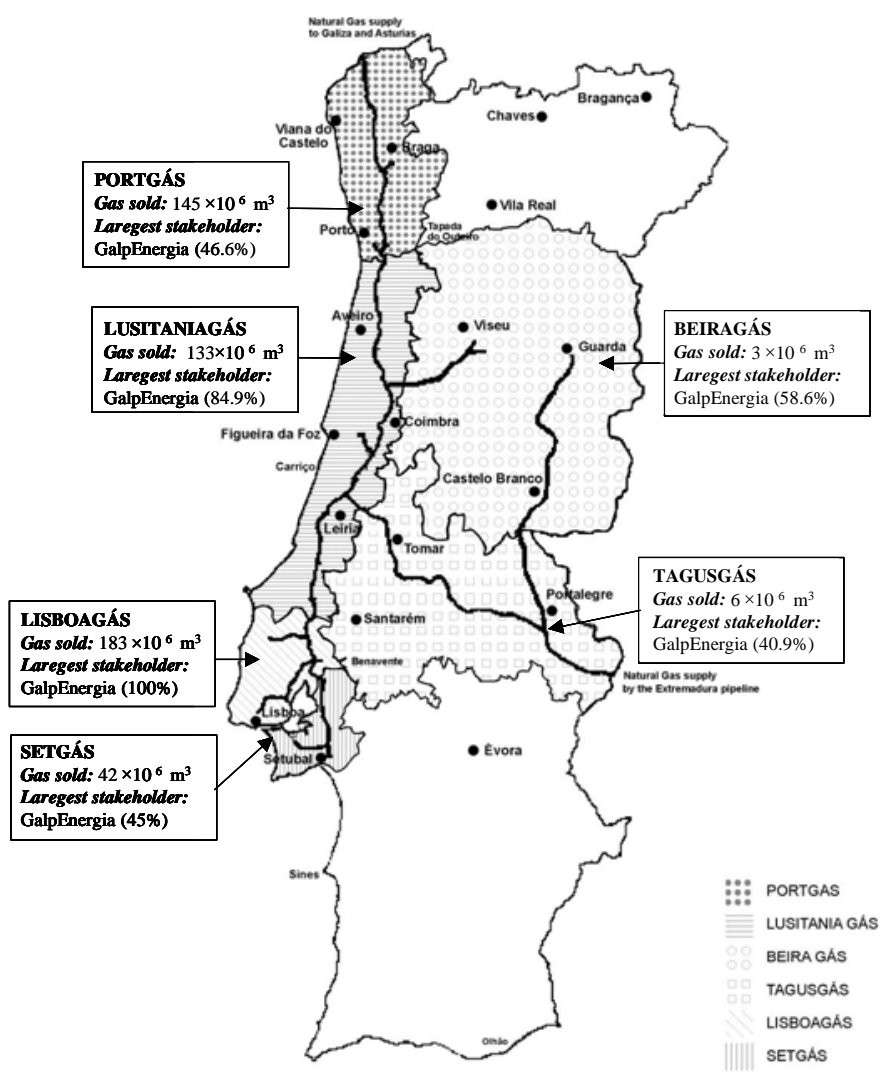

Figure 3- Geographical area of each distribution companies in Portugal (Source: Galp Energia, 2002)

The Beiragás and Tagusgás companies, that supply the Interior Centre of Portugal and the Valley of Tejo respectively, were created about five years later than the remaining distribution companies, thus presenting reduced activity. The distinct regional and urban characteristics of each one of the geographical areas with access to the natural gas, are a key factor to understand the different energy consumption structure and the strategies followed by the four major distribution companies.

The Atlantic North region is supplied by Portgás. In 2001, non-domestic users represented 73\% of the total volume of gas sold by this company. The domestic segment, although representing only $23 \%$ of the total amount of gas sold by Portgás, is the second largest among all the distribution companies, being only surpassed by Lisboagás. This is strongly related to the fact of the region supplied by Portgás has 24\% of the Portuguese global population. This is also a highly industrialised region: $32 \%$ of all the manufacturing industry is located in this region, with special incidence of the textile sector. 
Lusitaniagás is the distribution company that supplies the Centre Atlantic region of Portugal. It is a less populated region: $14 \%$ of the total population. This is reflected on the volume of gas sold, where the domestic sector represents only 15\%. As for the industrial sector, the total amount of gas sold in 2001 is the highest among all the distribution companies. This has to do with the industry typology of this region, characterized by high energy intensity manufacturing industries, specially the ceramic sector, formerly largely supplied by propane gas.

Lisboagás supplies the greater Lisbon metropolitan area. The natural gas consumption structure in this region presents an unique characteristic: the domestic and non domestic sectors are almost balanced. In 2001, non-domestic users represented $52 \%$ of the total volume of gas sold by this company and domestic users represented the remaining 48\%. In fact, the total amount of gas sold in 2001 for the domestic sector is by far the highest among all the distribution companies. This is the only region where a previous urban gas network already existed, supplying Lisbon with town gas. This fact allowed an easier entrance of natural gas. The town gas disappeared in 2002, and the consumers from Lisbon town represent about 58\% of the total Lisboagás clients (Lisboagás, 2002). The industrial typology of this region is characterised by a large diversity of sectors, including activities with high energy consumption processes like chemicals and food industries.

Setgás supplies the region of Setúbal peninsula (located to the south of Lisbon). This is the smallest of the four major distribution companies. In 2001, about $61 \%$ of the total volume of Setgás's gas was sold to non-domestic users. The replacement of propane gas by natural gas, is specially relevant in the domestic sector, where between 1999 and 2001 there has been a 90\% reduction of the propane gas consumption. This region is the least populated one, (only $7 \%$ of the total population), with the lowest number of manufacturing industries ( $6 \%$ of the total Portuguese manufacturing industry). Although being the region with the smallest electricity and propane consumption, the power generation activity makes it the largest fuel oil consumer.

Analysing the ownership structure of each of these privately owned independent companies, it is possible to conclude that the Galp Energia Group is the largest stakeholder of all the distribution companies, and the exclusive owner of the transport company. Galp Energia effectively controls all the Portuguese natural gas market: importation, storage, transportation, distribution and supply to large and small consumers. This way, the natural gas market presents a strong vertical integration.

It is also important to notice that the Galp Energia group also dominates the oil sector, once it is the exclusive owner of Petrogal (company that operates in the oil exploration, trading and supply). This is reflected in a strong relationship between oil and natural gas business, either by prices or through the control of both sectors by the same company. 
Galp Energia group has also some interests in the electricity field, once one of its stakeholders is EDPElectricidade de Portugal (the largest electricity company in Portugal), and operates also in the cogeneration area (Galp Power company).

The next section of this paper, explores the questions of how the present monopolistic structure of the natural gas market in Portugal influences its prices, and what will be the possible future scenarios in a liberalisation context.

\section{NATURAL GAS PRICES: A CRITICAL VARIABLE}

\subsection{DOMESTIC SECTOR}

For the domestic sector, this analysis includes the natural gas, the electricity and propane gas prices, considering the average prices on the $3^{\text {rd }}$ quarter of $2001^{(1)}$. The average prices, for each of the listed consumer categories are presented in Figure $4^{(2)}$. The results indicate that the natural gas prices are inferior to the electricity prices and to the propane gas prices, for every consumer category. As it would be expected, the smallest prices are associated with the larger consumers for every energy source analysed, but it is worth noticing that the D1 prices (small gas consumers) are inferior to the De prices (large electricity consumers) and to the D3p prices (large propane gas consumers).

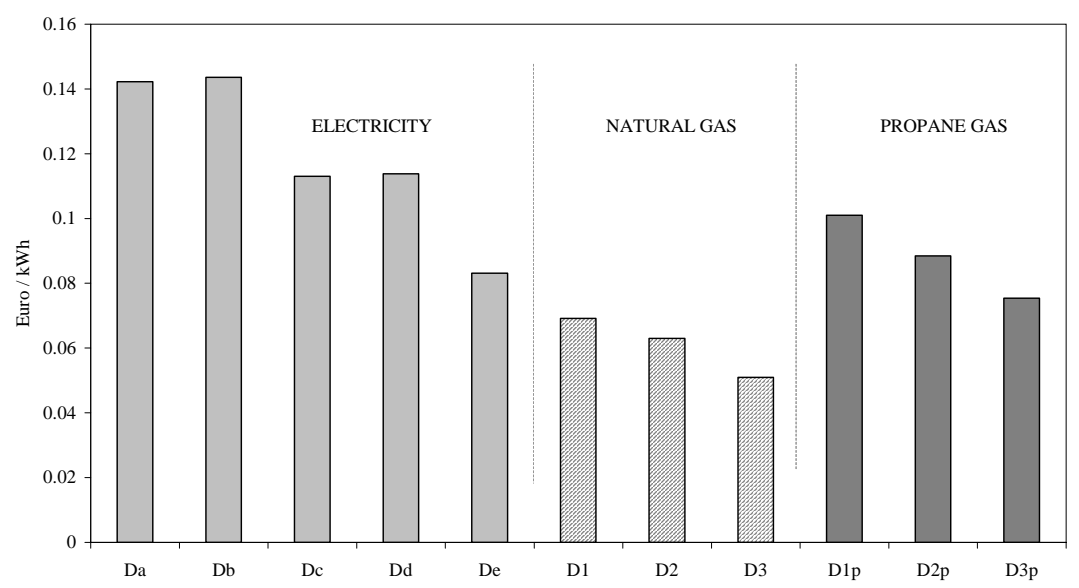

Electricity consumers: Da- 3kW contracted power; $600 \mathrm{kWh} /$ year consumption; Db- 3 to $4 \mathrm{~kW}$ contracted power; $1200 \mathrm{kWh}$ /year consumption; Dc- 4 to $9 \mathrm{~kW}$ contracted power; $3500 \mathrm{kWh} /$ year consumption (1300 kWh/year night); Dd- 6 to $9 \mathrm{~kW}$ contracted power; $7500 \mathrm{kWh} /$ year consumption (2500 kWh/year night); De- $9 \mathrm{~kW}$ contracted power; $20000 \mathrm{kWh} /$ year consumption (15000 kWh/year night). Natural gas consumers: D1- $2326 \mathrm{kWh}$ /year consumption; D2- 4652 kWh/year consumption; D3- $23260 \mathrm{kWh} /$ year consumption; D4- $290750 \mathrm{kWh} /$ year consumption. Propane consumers: D1p- 2332 kWh/year consumption; D2p- 4664 kWh/year consumption; D3p- 9328 kWh/year consumption.

Figure 4- Average domestic energy prices in Portugal (2001)

The higher propane prices, allied with the similar combustion efficiency of propane and natural gas together with small conversion costs, have been leading to the quick residence conversion to natural gas, 
and consequent reduction of the propane consumption in the domestic sector (Direcção Geral de Energia, 2002). We can expect that the domestic propane consumption will be confined to the geographic areas with no access to the natural gas or to older residences lacking a gas pipe system. In fact between 1999 and 2001, in the regions with access to the natural gas there was an average reduction of propane gas consumption of about $43 \%$, even achieving $90 \%$ reduction in the Setgás region. On the opposite, in the regions with no access to the natural gas, there was an increase of $14 \%$ in the propane gas consumption.

The conversion of electricity consumptions to natural gas is not as simple as it is from propane to natural gas. It involves high costs and some of the electricity consumptions can not be easily replaced by gas (see the example of lightning), meaning that the electricity have captive consumes. However, it is possible and worthwhile, to replace part of the electricity consumption, like water and environmental heating, especially in the case of small/medium electricity consumers and in new residences.

\subsection{INDUSTRIAL SECTOR}

For the industrial sector, this analysis includes the natural gas, the electricity, the propane and the fuel oil prices, considering the average prices on the $3^{\text {rd }}$ quarter of $2001^{(1)}$. The average prices, for each of these consumer categories are presented in Figure $5^{(3)}$. The results indicate that the natural gas prices are inferior to the electricity prices or to the propane gas prices, for every consumer category, but they are higher than the fuel oil prices for most of the natural gas consumer categories.

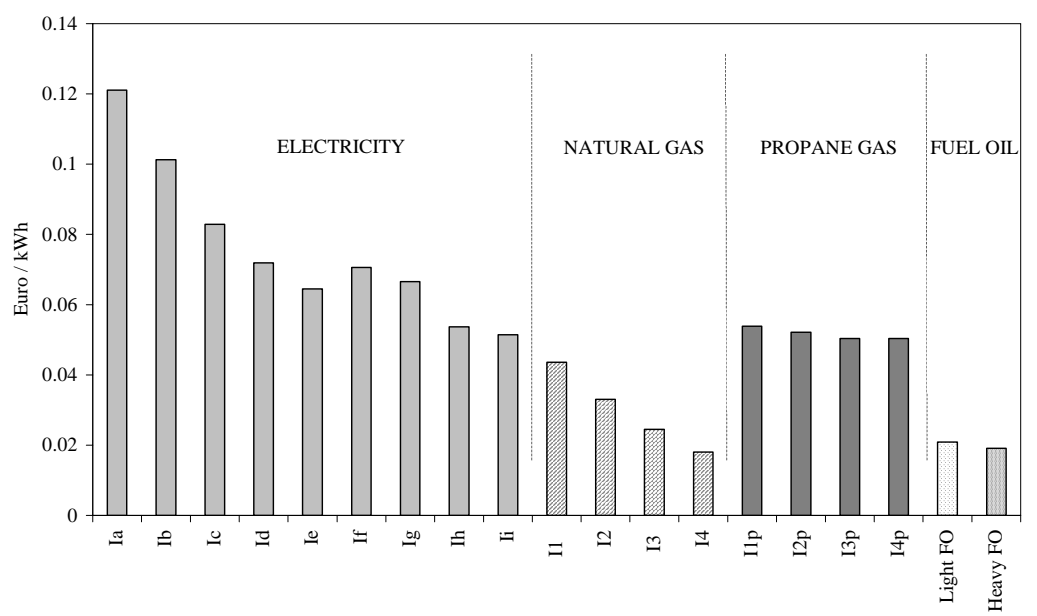

Electricity consumers: Ia- 30kW contracted power; $30000 \mathrm{kWh} /$ year consumption; Ib- 50kW contracted power; $50000 \mathrm{kWh} /$ year consumption; Ic- $100 \mathrm{~kW}$ contracted power; $160000 \mathrm{kWh} /$ year consumption; Id- 500kW contracted power; $1250000 \mathrm{kWh} /$ year consumption; Ie- $500 \mathrm{~kW}$ contracted power; $2000000 \mathrm{kWh} /$ year consumption; If- 2500 $\mathrm{kW}$ contracted power; $10000000 \mathrm{kWh} /$ year consumption; Ig- $4000 \mathrm{~kW}$ contracted power; $24000000 \mathrm{kWh} /$ year consumption; Ih- $10000 \mathrm{~kW}$ contracted power; $50000000 \mathrm{kWh} /$ year consumption; Ii- $10000 \mathrm{~kW}$ contracted power; $70000000 \mathrm{kWh} /$ year consumption Natural gas consumers: I1- $116245 \mathrm{kWh} /$ year consumption; I2- 1162452 kWh/year consumption; I3- $11624522 \mathrm{kWh} /$ year consumption; I4- $116245220 \mathrm{kWh} /$ year consumption. Propane consumers: I1p- 116245 kWh/year consumption; I2p- 1162452 kWh/year consumption; I3p- 11624522 kWh/year consumption; I4p- $116245220 \mathrm{kWh} /$ year consumption. 
Figure 5- Average industrial energy prices in Portugal (2001)

As in the domestic sector, the propane prices are leading to a quick decay of its consumption in the geographic areas with access to natural gas. The industrial processes which need a clean energy source can, easily and with a small cost, replace the propane gas by natural gas, obtaining a substantial reduction of its energetic costs. In the regions with access to the natural gas there was an average reduction of the propane gas consumption of 12\% between 1999 and 2001. In the other regions, the propane gas consumption for non domestic users grew by $18 \%$ in the same period. The region supplied by Lusitaniagás was the one where the propane gas consumption showed the largest reduction (56\% between 1997 and 2001). This is mostly justified by the large weight of the ceramic sector in this region, due to the high thermic energy intensity of this industry, formerly strongly dependent on the propane gas. In fact, even the Transgás (supplier of the larger consumers) assumes the ceramic sector as the largest natural gas consumer in the industrial sector, excluding cogeneration (GalpEnergia, 2002).

In what concerns the electricity consumption, in spite of its prices being higher than the natural gas prices, the industrial conversion has the problem of high costs as well as the electrical captive consumptions.

Only the heavy and light fuel oil present competitive prices in relation to the natural gas. The fuel oil prices are higher than the natural gas only in case of large gas consumers. However, it is likely that large fuel oil consumers have access to prices lower than the average ones used in this analysis, and small consumer will probably pay higher than average prices. These liquid fuels, present not only this apparent cost advantage, but also benefit from the fact of being on the market for many years, covering in 2000, 21\% of the industrial energetic needs in Portugal (Direcção Geral de Energia, 2002).

Between 1999 and 2001 there was a 20\% reduction of the fuel oil consumption in the non- domestic sector (including power generation) in the areas with access to the natural gas. The fuel oil consumption also decreased about $18 \%$ in the regions with no access to natural gas, for the same period. This way, during this period there was no clear influence of the natural gas on fuel oil consumption.

However, excluding the power production sector from the analysis the results indicate a $30 \%$ reduction of fuel oil consumption in regions with access to natural gas on opposition to the same $18 \%$ reduction in regions with no access to natural gas. The decrease of fuel oil consumption in non domestic sector (excluding power generation) achieves the highest value in the Portgás region: 39\% between 1999 and 2001. The textile industry has the most significant role on this reduction; in fact during this period the fuel oil consumption decreased $51 \%$ on this sector in the Atlantic North area of Portugal. These facts may result from the existence of some prices differentials of the fuel oil paid by the industrial consumers according to their size, leading to some cost advantages of the natural gas. 
In the future, we can foresee an environmental tax imposition charging the most pollutant fuels, which would lead to the rise of the fuel oil prices. The fuel oil environmental and maintenance disadvantages coupled with the higher efficiency combustion of the natural gas, will be the key factors for the future natural gas entrance in the fuel oil market.

The market liberalisation predicted for 2008, will allow the entrance of new competitors and it is possible that the incumbent companies will change the present price strategies, namely reducing the natural gas prices to levels near the European average, as it occurred in the electrical sector ${ }^{(4)}$.

\subsection{REgIONAL DIMENSION OF PRICES}

As it was already referred, the entrance of natural gas in the energy market, depends largely of the industrial and urban characteristics of the regions with access to it. This will probably lead to different strategies followed by the distribution companies, especially in what concerns price policies. Unfortunately the immaturity of the natural gas market, along with some lack of data, does not allow drawing many conclusions regarding these policies. However, some evidences may be pointed out.

For the domestic sector and considering 2001 prices, the Portgás company offers inferior prices to medium/large consumers than all the other distribution companies, but for smaller consumers their prices are higher than the average. The opposite happens with Lusitanigás whose prices are inferior than the average for small consumers and higher than average for large consumers. Considering the average price of all the consumer categories, Portgás and Lusitaniagás are those with smaller prices for the domestic sector. Setgás prices are close to average ones.

The Lisboagás prices are the highest for small/medium consumers ( $D_{1}$ and $D_{3}$ categories) and are also above the average of the four main distribution companies for every consumer categories. In part, these higher prices may result from the previous existence of a town gas network in Lisbon, which allows this company to have privileged access to a large group of clients who were already connected.

In the industrial sector the prices of the four distribution companies tend to be similar especially for the large consumers ( $\mathrm{I}_{3}$ and $\mathrm{I}_{4}$ consumer categories). For the $\mathrm{I}_{1}$ consumers, Portgás presented in 2001 the smallest prices and Lusitaniagás the smallest prices for $\mathrm{I}_{2}$ consumers. As in the domestic sector these two companies are those with smallest prices; Lisboagás average prices are the highest and Setgás prices are close to the average.

Considering these results, the natural gas entrance does not seem to have yet a significant impact on changing the regional cost structures, at least in what concerns the large industrial sector supplied by the 
distribution companies. For the smaller industrial sector our results indicate some regional differences that favour especially the Atlantic North and Center of Portugal.

According to our study, the regional production costs differences seem to be much more significant between regions with access to natural gas and regions with no access to it, rather than among regions already supplied.

At this moment, neither the number of data available nor the desegregation level allow us to go further. However, the Portuguese market is young and still growing. Only the future will tell us how, if and by how much this new form of energy allows cost advantages for the industrial sector. The study of evolution of the natural gas prices for a medium/long term period will be crucial to the clarification of price strategies followed by the companies and the consumption rates on each region.

\section{NATURAL GAS PRICES POLICIES IN THE EU}

Although in Portugal the liberalisation of the natural gas has been a delayed matter, most of the European countries are moving to the full opening of their markets. It is important to emphasise the United Kingdom (UK) market, which was pioneer in this process and where the full opening has been already achieved. It is now possible in UK for every consumer of electricity or natural gas, to choose his supplier.

From the previous price analysis for Portugal, we concluded that the natural gas present high competitive prices, in relation to the electricity or propane gas, but the fuel oil prices are still inferior to the natural gas ones.

In the UK, the electricity prices are substantially higher than the natural gas prices, for both the domestic and the industrial sector. On average, the electricity prices are 309\% higher than the natural gas prices in the domestic sector, and $284 \%$ higher than the industrial sector. Although the fuel prices were smaller than the natural gas prices during the beginning of the nineteen's, after 1994 this relationship was inverted and the fuel oil prices are now about $29 \%$ higher than the natural gas prices ${ }^{(5)}$.

The price differences in Portugal, are lower than in the UK. On average, the electricity prices in Portugal are about $109 \%$ higher than the natural gas prices in the domestic sector, and $150 \%$ in the industrial sector. The natural gas prices are higher than the fuel oil prices in about $34 \%$.

Comparing the natural gas prices in Portugal with the average prices of the liberalised European markets, it seems that the Portuguese prices are only slightly above the average European values for the consumer categories analysed in 2001. For the domestic sector the natural gas prices in Portugal were about 6\% 
higher than the European prices. For the industrial sector, the prices of natural gas in Portugal are about 2\% higher than the EU prices. ${ }^{(6)}$

However, it is also important to notice that the natural gas taxes in Portugal are amongst the smallest in the EU, representing only 5\% (VAT) of the total price. Meanwhile, the average taxes in the EU are about $30 \%$ of the total price. This means of course that the net prices charged by the Portuguese companies are much higher than the European ones. Considering these net values, it is possible to conclude that, the Portuguese prices are amongst the highest in the EU, for all the consumer categories analysed. On average, the natural gas prices in Portugal are 20\% higher than the European ones for the domestic sector and $22 \%$ higher for the industrial sector.

Analysing these results, we can conclude that the present gas companies seem to follow a strategy of profit maximisation, in the pre-liberalisation period, taking advantage of the reduced tax rates. They practice prices sufficiently low to allow them to capture some clients from the electricity and propane market, but they still maintain their prices well above the European ones. To capture clients from the fuel oil market, the natural gas companies do not seem to intend to follow a price reduction strategy. The clients will probably be attracted by the environmental and other technical advantages associated with the cleaner combustion process.

Also, a comparison with the natural gas market in Spain, tells quite a similar story. Once more, the Portuguese net prices for domestic sector are about 19\% higher than the Spanish ones. This difference directly increases with the size of the consumer. For the industrial sector, the prices of natural gas in Portugal are about $48 \%$ higher than the Spanish prices, due to the highly competitive prices of natural gas to industry in Spain, that are amongst the smallest in Europe.

Considering these examples and the present market structure in Portugal the future liberalisation process must address questions like: the effective control of the market by the regulator entity, the unbundling of the natural gas industry and the regulated third party access to the transportation and distribution networks.

We can also foresee the development of new market mechanisms. In case of the present companies committed with long term take-or-pay buying contracts, they may be obliged to re-sell their contracted gas (due to regulatory or competitive restrictions), as it occurred in the UK. The present companies can also follow a diversification strategy, acting in several activities of the energy market, following the example of the British Gas strategy. The electricity market will be increasingly associated with natural gas market, due to the expected development of power generation from natural gas, consolidating a gasto-power strategy in Portugal 


\section{CONCLUSIONS}

According to the results of this study, it is clear that the present monopolistic structure and the taxes advantages, allow the Portuguese natural gas companies to practice a price strategy that would hardly be possible in a competitive market.

Considering examples of other countries in the European Union, future possible scenarios for Portugal were defined. The effectiveness of the liberalisation process will depend on what will be the future State intervention. The regulatory system will have a fundamental role in the achievement of a reasonable number of competitors in the market. With the development of the Iberian Energy Market, Spanish companies can also be a significant active part, contributing to the Portuguese market dynamization and to the harmonisation of tariffs. Meanwhile, it can be expected that the implementation of the Iberian Electricity Markets and full liberalisation of the Spanish natural gas market will carry out the anticipation of the Portuguese natural gas market liberalisation.

Due to its present market structure and to the liberalisation perspectives, Portugal is a very interesting case study. Following the present study, in future research, it is possible to analyse and monitor the development of the Portuguese energy market, studying the pricing policies followed by the natural gas companies before and after the liberalisation and how it did affect the other energy prices.

The existence of regions with access to natural gas and regions with no access to it, allows to analyse the rate of acceptance of this new fuel on the energy market. In fact, in the regions with access to natural gas we have been witnessing to a clear reduction on the consumption of its most direct competitors (propane gas and fuel oil). This indicates that the consumers are aware of its most obvious economical advantages: lower cost than propane gas and higher combustion efficiency than fuel oil.

Additionally, the regional dimension of the market raises the question of how the production costs of industries located in different Portuguese regions will be affected. The existence of a more competitive energy market may bring a cost advantage to the consumers located in regions supplied by natural gas, relatively to the consumers in the other regions, giving them a competitive advantage in the global markets. However, the positive impact of the natural gas introduction on regional development is not yet clear, namely in what concerns the inward due to its relatively recent arrival.

The existence of significant price differentials among the regions supplied by the natural gas, was also analysed. However, the results do not show great differences on the price policies presently followed by the supplying companies. This way, the regional production costs asymmetries, seam to be especially relevant between companies located in regions with access to the natural gas and companies with no access to it. 
Future research is necessary to explore the relationship between the industrial energy costs and the companies competitive advantage, taking into consideration the different energy intensity of the several industrial sectors. The development of the still young Portuguese market will help us to have more and reliable information. This will allow us, to have a better understanding of relevant issues like the regional consequences of the natural gas entrance, the price strategies followed by the distribution companies and the impact upon the industrial production costs.

\section{ENDNOTES}

(1) Data analysis from 1998 till 2001 is available under request from the authors.

(2)The natural gas consumer categories and average prices were obtained in DGE site (www.dge.pt). The electricity consumer categories and average prices were obtained in Eurostat (2001a).The propane gas consumer categories were defined by the authors, and the average prices were calculated using the price list of one regional distribution company.

(3) The natural gas consumer categories and average prices were obtained in DGE site (www.dge.pt). The electricity consumer categories and average prices were obtained in Eurostat (2001b).The propane gas consumer categories were defined by the authors, and the average prices were calculated using the price list of the industrial distribution company. The average fuel oil price was obtained in the Oil Bulletin published monthly by the European Commission (http://europa.eu.int/comm/energy/en/oil/bulletin_en.html)

(4) In 1995, the average net electricity prices in Portugal were 35\% higher than the European average for the domestic sector and $62 \%$ for the industrial. After the liberalisation, this difference was reduced to $10 \%$ for the domestic sector and 9\% for the industrial sector in 2001 (Eurostat, 2001 a and b and Department of Trade and Industry, 2002).

(5) Values based on information from the Department of Trade and Industry (2002).

(6) Values based on information from Eurostat (2001 c and d).

\section{REFERENCES}

Commission of the European Communities (2002), "Second report on the implementation of the internal electricity and gas market”, Commission Staff Working Paper, SEC(2002) 1038

Commission of the European Communities (2001), "Completing the internal energy market", Commission Staff Working Paper, SEC(2001) 438

Department of Trade and Industry (2002), Quarterly energy prices- September 2002 (http://www.dti.gov.uk/energy/inform/energy_prices/index.shtml)

Direcção Geral de Energia (2002), O gás natural em Portugal: Uma perspectiva integrada (www.dge.pt) 
Dri Wefa (2001a) "Report for the European Commision to determine changes after opening of the gas market in August 2000", Vol I: European Overview, July 2001

Dri Wefa (2001b) "Report for the European Commision to determine changes after opening of the gas market in August 2000", Vol II: Country Reports, July 2001

Energy Information Administration (2002), "International Energy Outlook 2002", DOE/EIA-0484(2002)

European Commission (1995), "White paper- An energy policy for the European Union", Com(95)682

European Commission (2002), "European Union- Energy \& Transports in figures 2002", DirectorateGeneral for Energy and Transport (http://europa.eu.int/comm/energy_transport/etif/index.html)

Eurostat (2001a), "Electricity prices for EU households on 1 July 2001", Statistics in Focus, Theme 824/2001 (http://www.eu-datashop.de/service/EN/infos/sta_kurz/thema8/stat_k_8.htm)

Eurostat (2001b), "Electricity prices for EU industry on 1 July 2001", Statistics in Focus, Theme 8$25 / 2001$

Eurostat (2001c), "Gas prices for EU households on 1 July 2001", Statistics in Focus, Theme 8- 22/2001

Eurostat (2001d), "Gas prices for EU industry on 1 July 2001", Statistics in Focus, Theme 8- 23/2001

Ferreira, P. (2002) "O gás natural a caminho da liberalização: Uma contribuição através da metodologia VAR", Dissertação de Mestrado, Faculdade de Economia do Porto

Galp Energia (2002), Relatório de Gestão. Contas Consolidadas

International Energy Agency (2000), Energy policies of Portugal. 2000 Review

Juris, A. (1998), "Market development in the United Kingdom's natural gas industry", Policy Research Working Paper 1890, World Bank

Lisboagás (2002) Relatório e Contas 2002- Lisboagás (www.galpenergia.com)

Oxera (2000), Energy liberalisation indicators in Europe, October 2000

(http://www.dti.gov.uk/energy/publications/policy/index.shtml)

http://europa.eu.int/comm 
http://europa.eu.int/comm/energy/en/oil/bulletin_en.html www.dge.pt

www.dti.gov.uk

www.eia.doe.gov

www.galpenergia.com 